\title{
A case of acute respiratory failure due to bronchial rupture of an intrapulmonary cyst
}

\author{
Atsushi Hata ${ }^{1 *}$, Takekazu Iwata ${ }^{1}$, Akira Naito², Yoko Takahashi ${ }^{3}$, Yasuo Takiguchi ${ }^{2}$, Yukio Nakatani ${ }^{3,4}$, Shigetoshi Yoshida ${ }^{1}$ and \\ Ichiro Yoshino ${ }^{1}$ \\ *Correspondence: atsushata@gmail.com

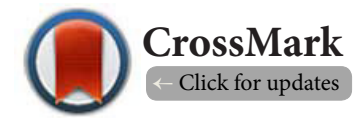 \\ 'Department of General Thoracic Surgery, Graduate School of Medicine, Chiba University, Chiba, Japan. \\ 2Department of Respirology, Chiba Aoba Municipal Hospital, Chiba, Japan. \\ ${ }^{3}$ Department of Pathology, Chiba University Hospital, Japan. \\ ${ }^{4}$ Department of Diagnostic Pathology, Graduate School of Medicine, Chiba University, Chiba, Japan.
}

\begin{abstract}
Background: The bronchial rupture of intrapulmonary cyst is very rare. We describe a case of bronchial rupture of intrapulmonary cyst which caused acute respiratory failure. A 31-year-old pregnant woman was taken to our hospital with acute respiratory failure. Chest radiography showed right atelectasis. After cesarean with endotracheal intubation, the atelectasis and respiratory failure immediately improved. However, several days later she was suffered with dyspnea with right atelectasis again. Bronchoscopy revealed necrotic material obstructing the right upper bronchus. After she continued to expectorate necrotic material, chest computed tomography revealed an empty cyst in the right upper lobe. Bronchoscopy showed cecal cystic bronchiectasis and absence of the B1/2 bronchi. We diagnosed as intrapulmonary cyst caused by the bronchial atresia of B1/2. Presuming that the contents of the ruptured intrapulmonary cyst caused acute respiratory failure, we performed a right upper lobectomy. Although intrapulmonary cysts are often asymptomatic, life-threatening rupture can occur suddenly. We believe that the cyst's potential for bronchial rupture is an indication for surgery.
\end{abstract}

Keywords: Intrapulmonary cyst, bronchial rupture, bronchial atresia, bronchial cyst

\section{Introduction}

Respiratory symptoms resulting from the rupture of peribronchial/tracheal cysts are rarely reported. We report herein a rare case in which the contents of an intrapulmonary cyst caused acute respiratory failure.

\section{Case presentation}

A 31-year-old woman had a history of asthma, hypoplasia of the right upper lobe on computed tomography, and repeated episodes of pneumonia from childhood. She began to experience asthmatic symptoms in the 32 nd week of pregnancy and was treated as asthma by her primary physician. Two weeks later, she was taken to the emergency department for severe dyspnea. Blood gas analysis on $100 \%$ oxygen inhalation revealed a partial pressure of oxygen of 76.4 Torr. Despite a lack of a hematological inflammatory reaction, chest radiography showed a broad low-density area in the right lung field (Figure 1). After a cesarean was performed under general anesthesia with endotracheal intubation, her respiratory condition and the radiological findings immediately improved, and she was extubated on the first postoperative day.

However she had recurrent dyspnea on the ninth postoperative day. Bronchoscopy revealed necrotic material obstructing the entrance to the right upper lobar bronchus. She continued to expectorate necrotic material and chest computed tomography finally revealed an empty cyst instead of B1/2, persistent atelectasis and a dilated B3 in the right upper lobe (Figure 2). Repeat bronchoscopy revealed an empty cecal cyst where B1/2 should have been (Figure 3). B3 was observed as an ectatic bronchus filled with sputum.

We speculated that this intrapulmonary cyst ruptured into the airway, with the contents of the cyst flowing into the lower bronchi and obstructing the middle/lower lobes, causing repeated episodes of dyspnea. We performed a right upper lobectomy in order to prevent reaccumulation of the cystic contents and the recurrence of the airway obstruction. The postoperative period was uneventful.

Gross examination revealed that most of the upper lobe had been replaced by a cyst, and no B1/2 bronchi were observed. Microscopically, the cyst was lined by bronchial epithelium and had a fibrous wall, which included some bronchial glands and cartilages (Figure 4). Pathological diagnosis was intrapulmonary cyst formed by bronchial atresia.

\section{Discussion}

Judging from the clinical history, we speculate that this was a 


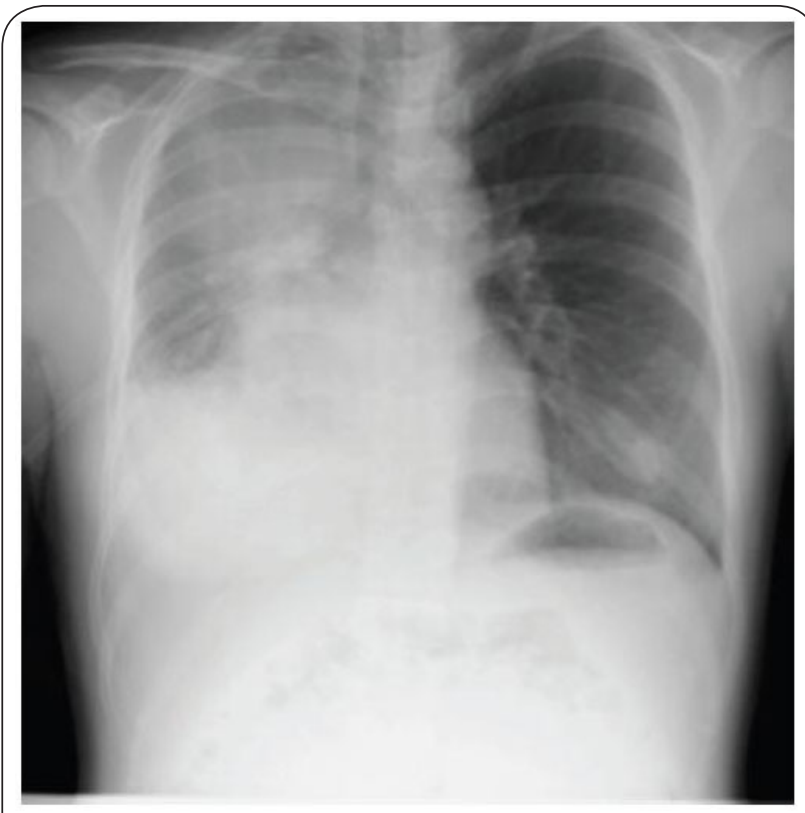

Figure 1. Chest radiography showed a broad low-density area in the right lung field.

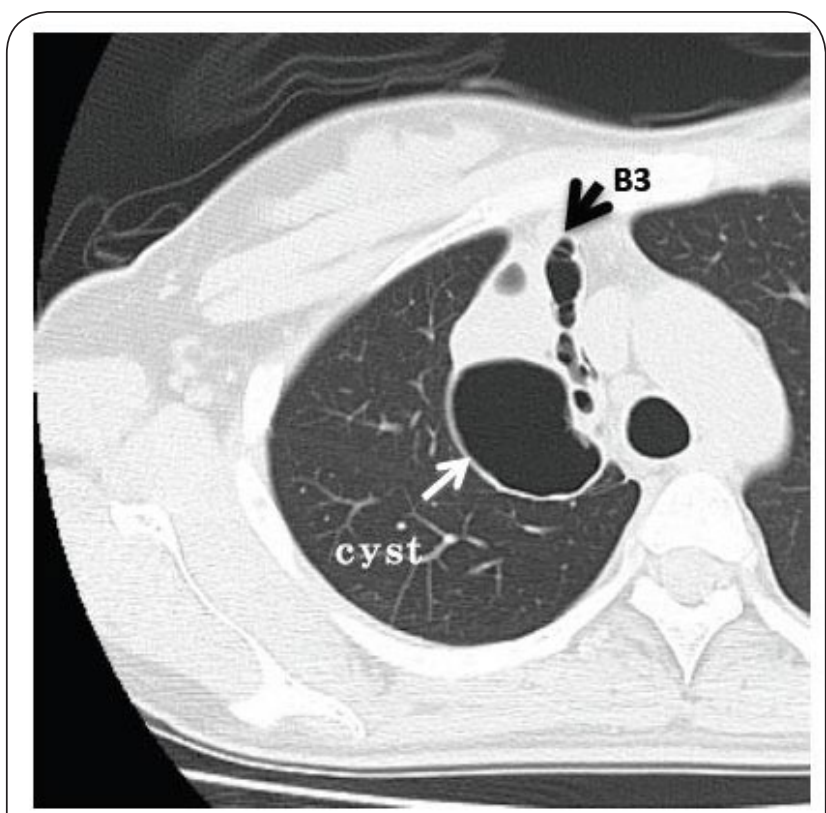

Figure 2. Chest computed tomography revealed an empty cyst, persistent atelectasis, a dilated B3 and no evidence of $\mathrm{B} 1 / 2$ in the right upper lobe.

congenital intrapulmonary cyst: bronchial cyst or congenital bronchial atresia. Bronchial cyst develops from aberrant separation of the bronchus during embryonic development; the cyst is the result of mucocele expansion in the separated bronchus. Bronchial atresia is a congenital obstruction of the normal bronchus, with peripheral bronchial dilation and

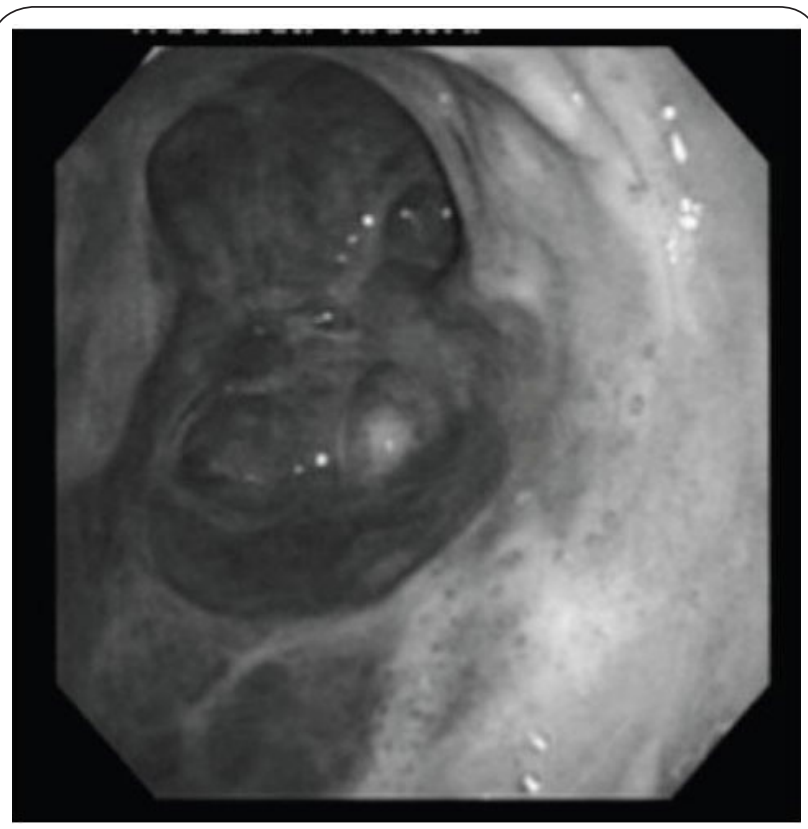

Figure 3. Bronchoscopy revealed an empty cecal cyst was seen where $B 1 / 2$ should have been.

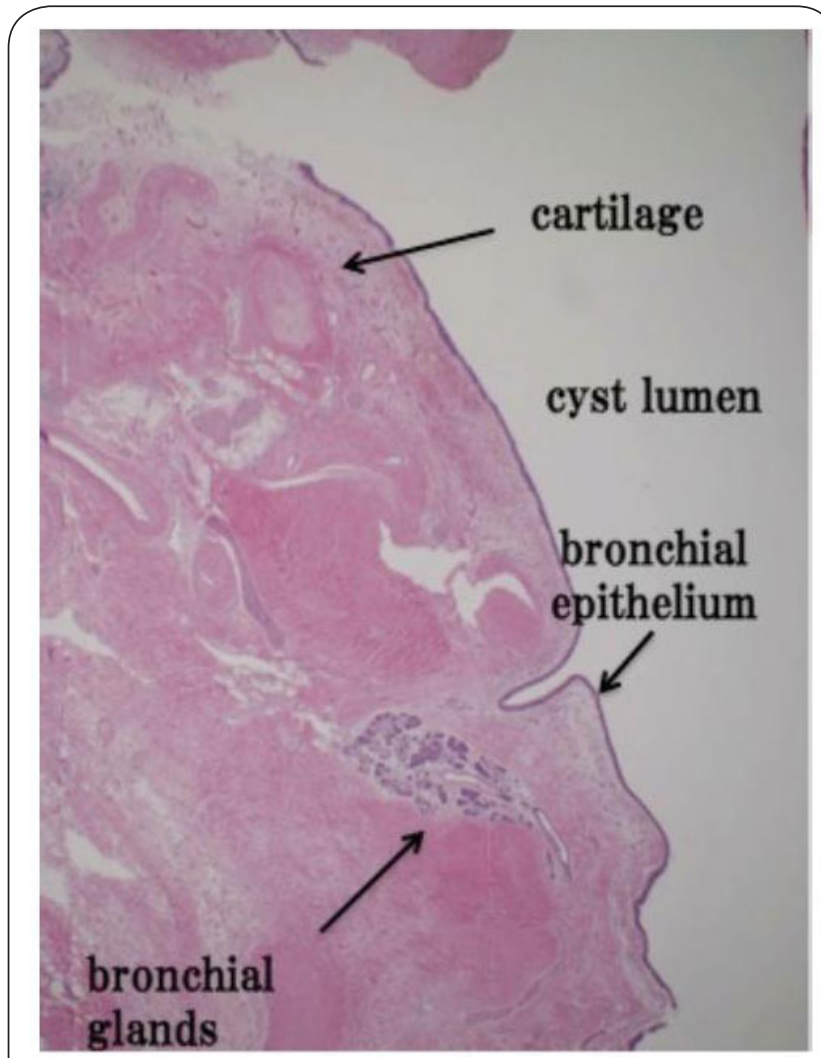

Figure 4. Microscopically, the cyst was lined by bronchial epithelium and had a fibrous wall, which included some bronchial glands and cartilages (H\&E, Loupe imaging).

mucus pooling. Mucoceles resulting from bronchial atresia 
demonstrate dilation of the peripheral bronchus, caused by obstruction of the normal bronchus at the hilum [1]. In our patient the cyst replaced B1 and B2, suggesting that bronchial atresia was the culprit. Also pathological examination revealed intrapulmonary cyst formed by bronchial atresia.

Ramsay et al., [1] purport that rupture of the obstructing septum of a dilated mucocele caused by bronchial atresia may be the origin of congenital bronchiectasis. Rupture of cysts caused by bronchial atresia has not been reported in adults, but rupture of mediastinal bronchial cysts has been seen $[2,3]$. Amylase is usually secreted from bronchial glands [4]; therefore, if the wall of a cyst is lined by bronchial epithelium, it is possible that the amylase could cause bronchial cyst rupture.

Both intrapulmonary bronchial cysts and bronchial atresia often cause no symptoms in the absence of infection or cystic dilation and the patients only require follow-up observation $[5,6]$. However, clinicians should be alert for the possibility of bronchial cyst rupture which is capable of causing major, life-threatening airway obstruction.

\section{Conclusion}

Although intrapulmonary cysts caused by bronchial atresia are often asymptomatic, life-threatening rupture can occur suddenly. On the basis of our experience with the patient described in this report, we believe that the cyst's potential for bronchial rupture is an indication for surgery.

\section{Competing interests}

The authors declare that they have no competing interests.

\section{Authors' contributions}

\begin{tabular}{|l|c|c|c|c|c|c|c|c|}
\hline Authors' contributions & AH & TI & AN & YT1 & YT2 & YN & SY & IY \\
\hline Research concept and design & $\checkmark$ & $\checkmark$ & -- & -- & -- & -- & $\checkmark$ & $\checkmark$ \\
\hline Collection and/or assembly of data & $\checkmark$ & $\checkmark$ & $\checkmark$ & $\checkmark$ & $\checkmark$ & $\checkmark$ & -- & $\checkmark$ \\
\hline Data analysis and interpretation & $\checkmark$ & $\checkmark$ & -- & -- & -- & $\checkmark$ & $\checkmark$ & $\checkmark$ \\
\hline Writing the article & $\checkmark$ & -- & -- & -- & -- & -- & -- & -- \\
\hline Critical revision of the article & -- & $\checkmark$ & -- & -- & -- & $\checkmark$ & -- & $\checkmark$ \\
\hline Final approval of article & $\checkmark$ & $\checkmark$ & $\checkmark$ & $\checkmark$ & $\checkmark$ & $\checkmark$ & $\checkmark$ & $\checkmark$ \\
\hline Statistical analysis & -- & -- & -- & -- & -- & -- & -- & -- \\
\hline
\end{tabular}

\section{Publication history}

EIC: Joseph Varon, University Of Texas Medical Branch, USA.

Received: 02-Mar-2014 Final Revised: 03-May-2014

Accepted: 08-May-2014 Published: 14-May-2014

\section{References}

1. Ramsay BH. Mucocele of the lung due to congenital obstruction of a segmental bronchus; a case report; relationship to congenital cystic disease of the lung and to congenital bronchiectasis. Dis Chest. 1953; 24:96-103. | Article | PubMed

2. Sundaramoorthi T, Mahadevan R, Nedumaran K, Jayaraman S and Vaidyanathan KR. Intrabronchial rupture of bronchogenic cyst. Ann Thorac Surg. 2009; 87:1919-20. | Article | PubMed

3. De Nunzio MC and Evans AJ. Case report: the computed tomographic features of mediastinal bronchogenic cyst rupture into the bronchial tree. Br J Radiol. 1994; 67:589-90. | Article I PubMed

4. Hayashi Y, Fukayama M, Koike M and Nakayama T. Amylase in human lungs and the female genital tract. Histochemical and immunohistochemical localization. Histochemistry. 1986; 85:491-6. | Article I PubMed

5. Meng RL, Jensik RJ, Faber LP, Matthew GR and Kittle CF. Bronchial atresia. Ann Thorac Surg. 1978; 25:184-92. | Article | PubMed

6. Patel SR, Meeker DP, Biscotti CV, Kirby TJ and Rice TW. Presentation and management of bronchogenic cysts in the adult. Chest. 1994; 106:79-85. | Article | PubMed

\section{Citation:}

Hata A, Iwata T, Naito A, Takahashi Y, Takiguchi Y, Nakatani Y, Yoshida S and Yoshino I. A case of acute respiratory failure due to bronchial rupture of an intrapulmonary cyst. Emerg Med Health Care. 2014; 2:1. http://dx.doi.org/10.7243/2052-6229-2-1 